\title{
Understanding the Economics of Transportation Projects
}

\author{
Grant G. Schultz ${ }^{1}$ and Jeremy E. Searle ${ }^{2}$ \\ ${ }^{1}$ Department of Civil \& Environmental Engineering, Brigham Young University, 368 Clyde Building, Provo, UT 84602, USA \\ ${ }^{2}$ Project Engineering Consultants, Inc., 397 W. 400 N., Payson, UT 84651, USA
}

Correspondence should be addressed to Grant G. Schultz, gschultz@byu.edu

Received 21 March 2012; Revised 1 May 2012; Accepted 2 May 2012

Academic Editor: Thanasis Stengos

Copyright ( 2012 G. G. Schultz and J. E. Searle. This is an open access article distributed under the Creative Commons Attribution License, which permits unrestricted use, distribution, and reproduction in any medium, provided the original work is properly cited.

\begin{abstract}
Understanding the economic impacts of transportation projects is essential for decision makers, officials, and stakeholders as they determine the best course of action for their jurisdiction. Economic impacts can guide decisions of future projects and help explain past economic fluctuations. This study uses an evaluative (ex-post) analysis process to assess the generative economic impacts of transportation projects after completion that can be used to identify the economic impacts of transportation projects while quantifying their relationship. Both pre- and postconstruction data were collected and used to compare the trends of sales tax revenue and employment numbers adjacent to transportation projects in Utah over a 10-year period. Plots of the trends before, during, and after construction for each project in the analysis were generated. A formal process was created for completing the analysis for future study. Results indicate that there is a positive relationship between transportation improvement projects and sales tax revenues. This relationship amounts to approximately a 4.0 percent increase in trends compared to the state overall. Employment demonstrated a 4.5 percent increase compared to the state overall. Although the results are not considered statistically significant, they are considered practically significant and add to the literature on this topic.
\end{abstract}

\section{Introduction}

Transportation projects influence the economy in a variety of ways. Understanding the economic impacts of transportation projects is essential for decision makers, officials, and stakeholders as they determine the best course of action for their jurisdiction. Economic impacts can guide decisions of future projects and help explain past economic fluctuations. It is important to identify a process that can be used to evaluate the economic impacts of transportation projects and further refine that process to increase the understanding of economic impacts of transportation projects.

The purpose of this study is to identify types of economic impacts that result from transportation projects and provide a better understanding of their relationship. This is done by evaluating the changes in sales tax and employment before and after a transportation project is completed. The state of Utah is used as a case study to develop an analysis process.

Accomplishing the objectives of this study is a product of (1) performing a comprehensive literature review, (2) identifying a method to address the effects of the recession,
(3) collecting data and establishing analysis methods, (4) completing a statistical analysis and breakdown into project type and expenditure values, and (5) conclusions and recommendations.

\section{Literature Review}

A literature review was completed to better understand the economic impacts of transportation projects, to learn about the transportation-economic relationship, and to examine the results of previous studies on the subject. A brief summary of the literature review is presented in the following paragraphs.

It is important to identify the type of economic impact when performing an analysis. Types of impacts vary with different researchers, but the Transportation Research Board (TRB) has provided a standard classification system of three types of economic impacts: (1) generative, (2) redistributive, and (3) financial transfer impacts [1].

There are two basic types of economic impact analysis: (1) predictive and (2) evaluative [1]. These two basic 
types of analysis can be disaggregated into numerous methods for analyzing economic impacts of transportation projects. These methods include case studies, computer models, input-output models, statistical and nonstatistical comparisons, surveys, benefit/cost analysis, and others. It is important to identify the correct method and procedure to avoid bias and obtain correct results.

Increasingly computer models are being used to provide results for government agencies. Although these programs can provide useful results for decision makers, the accuracy of these results depends greatly on the dependability of the data and the ability of the modeler to manipulate the program to correctly represent specific situation(s) [2].

State Departments of Transportation (DOTs) are beginning to incorporate economic impacts into their project prioritization process. This transition to evaluating the economic impacts of a transportation project will allow state DOTs to better maximize the benefit to users and the overall economy [3-5].

Numerous studies attempting to identify economic impacts of transportation projects have been completed. Several state DOTs, including Wisconsin and Indiana, have completed studies looking at the increase in jobs, costbenefit ratios, consumer spending and sales tax increases, and other impacts. Effects on sales tax, employment, and personal income are particularly important when attempting to determine the overall impact on the local economy $[6,7]$.

Several studies have been completed in the state of Utah regarding the economic impacts of transportation projects [8], focusing on the financial transfer impacts of federally funded transportation infrastructure along the Wasatch Front. This study identified the funding for the Utah Transit Agency (UTA), the Wasatch Front Regional Council (WFRC), and Mountainland Association of Governments (MAG) and predicted jobs created by these funds and additional jobs. State income taxes and the increase in Gross State Product (GSP) were also forecasted. Envision Utah also funded a study on the economic impacts of expanding public transportation along the Wasatch Front [9]. This study estimated the cost-benefit ratio, increase in jobs and personal income, and user benefits to the public.

The literature review also indicated that although there are many different variables that are influenced by transportation projects, there are a few that are more important to the public and government agencies. Through the course of the research, two variables were identified in this study as key indicators for how a transportation project affects the economy. These include (1) sales tax and (2) employment. These two indicators include factors that are most important to both the public and government agencies. The indicator that the public is most concerned with is the number of jobs created, and government agencies are most concerned with sales tax revenues [3-6, 10, 11].

\section{Recession Concerns}

Beginning in 2007, and extending into the timeframe of this analysis (2010), the economy experienced a worldwide recession. Unemployment rose while the health of the economy plummeted. The recession and other variations in the economy are concerns that will present challenges for any locality attempting to quantify the economic impacts of transportation projects in their area.

Dealing with the effects of the recession presents several problems, bringing to mind questions such as How does the overall economy affect the results of the analysis? Does a recession negate the positive economic impacts of a transportation project-or merely lessen the severity of the recession? What can be done to determine what the sales tax or employment trends in a local area would have been without the transportation project? All of these questions affect the results of the analysis and how the results should be viewed and used.

When there are variables that influence the outcome of a comparative study, as the recession does in this study, it is necessary to provide a comparison group that also experienced the same confounding variable, but did not experience the object of the study, in this case a transportation project. Since this study covers a period of 10 years, it was not feasible to identify a representative location in Utah that did not include a transportation construction project at some point during the analysis years. Therefore, the comparison used against each transportation project was the trends for the overall state.

To account for the recession and other variability in the economy, all analyses were completed by normalizing local values by overall state numbers. This produced a local ratio for the state. This ratio over time shows the trend compared to the state. If the trend over time is flat, then the local area has been growing (or declining) at the same rate as the state. If the trend is positive, then the local area is growing faster (or declining less) than the state. If the trend is negative, then the local area is growing slower (or declining more) than the state. Comparing the trends before, during, and after a transportation construction project against the overall state trend provides insight as to how the specific transportation project influenced the economy in that area.

\section{Collecting Data and Analysis Methods}

There are two basic types of economic impact analysis: (1) predictive and (2) evaluative. The analysis presented here is an evaluative (or ex post) analysis of transportation projects after completion. Both pre- and postconstruction data were collected and compared to determine the effect that each project had on the local economy in terms of sales tax revenue and employment. A statistical comparison was used to determine if the means of the preconstruction and postconstruction were significantly different.

Three different databases were gathered and used in this study. They are

(1) transportation project database,

(2) state sales tax by zip code database,

(3) state employment database. 
Similar databases should be available in any jurisdiction. In this case, the case study was completed in Utah, and these databases were collected from the Utah Department of Transportation (UDOT), the Utah State Tax Commission, and the Utah Division of Workforce Services (DWS). Both pre- and postconstruction data were collected and used to compare the trends of sales tax revenue and employment creation adjacent to transportation projects. More detailed information on each of the databases, as well as the results of their analysis and the overall analysis process, is presented in the following sections.

4.1. Transportation Project Database. The transportation project database is the most important database used in the analysis. The case study presented here used a transportation project database made available by UDOT; however, not all of the information was complete, so only a portion of the projects could be used in the analysis.

4.2. Sales Tax Analysis. To complete the sales tax analysis, zip codes for the location of each project were identified. Each project was then matched with the corresponding sales tax history for the zip code (1996-2009). Matching the project with the zip code was used for this analysis; however, if more disaggregate sales tax data were acquired, this would be recommended to be done using Geographic Information System (GIS) software. For all analyses undertaken in this study, all dollar values have been adjusted for inflation to 2009 dollars [12]. Only projects that included adequate location data were used in the analysis. Projects that were completed in 2009 were not used due to a lack of after data. Also projects that took place in areas that had zero sales tax for any of the analysis years were also not used because these areas are too rural to have a sales tax base. All sales tax data were then normalized (divided) by state sales tax values. Doing this controlled for the recession and other fluctuations in the economy as outlined previously. When evaluated over time, these values show a trend of the local area compared to the state. Based upon these trends, a plot was generated for each project. A single project is used here as an example. The example project was a reconstruction project that widened the Redwood Road corridor to four lanes from 9000 South to 10400 South in West Jordan, Utah. Construction took place from 2002 to 2004. Figure 1 shows the plot completed for this project.

Each plot shows three trends: (1) preconstruction, (2) during construction, and (3) postconstruction. Only the preand postconstruction trends are used in the analysis. Four years was used as the amount of time for the preconstruction trend because this was the longest amount of postconstruction data that were available. Jurisdictions can decide on the amount of time used in the pre- and postconstruction trends depending on need and availability of data; however, preand postconstruction trends are recommended to cover a similar length of time. This particular project shows a slightly positive trend compared to the state before construction. After the construction is completed, the trend increases, showing that the area along Redwood Road is growing faster than the state after the completion of the project.

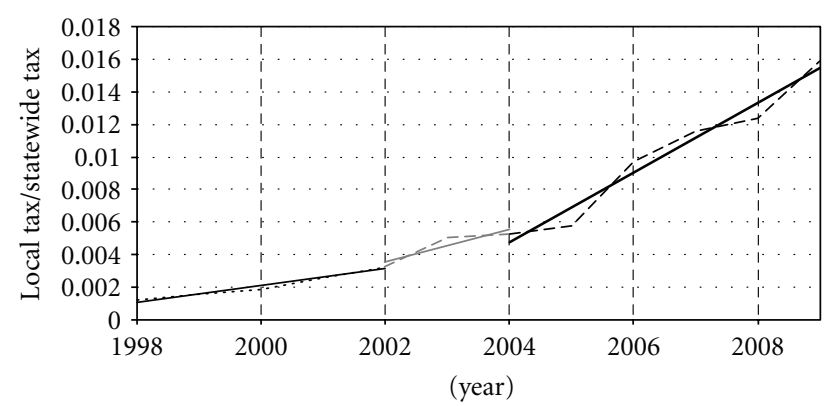

$$
\begin{aligned}
& \text {.... Local tax/statewide tax preconstruction } \\
& -- \text { Local tax/statewide tax postconstruction } \\
& - \text { Trend during construction } \\
& -- \text { Local tax/statewide tax during construction } \\
& - \text { Preconstruction trend } \\
& - \text { Postconstruction trend }
\end{aligned}
$$

Figure 1: Sales tax/statewide tax around reconstruction project on Redwood Road.

4.3. Employment Analysis. The employment data obtained from DWS listed every business in the state of Utah, along with a physical address and the number of employees each month from 2000 to 2009. The physical address provided a means to locate the businesses affected by a transportation project. Using the given addresses, the entire employment database was geo-coded into a GIS format, which provided a map of every business in Utah. UDOT projects were also geo-coded and could be seen on the same map. Only projects that had enough location data recorded could be geo-coded. This amounted to 508 of the 2,720 projects included in the project database obtained through UDOT.

Using ArcMap, a GIS software package, a model was written that would select each transportation project and create a quarter mile radius buffer around the project site. A quarter mile (1,320 feet) was used to include all businesses that would be affected by the construction, but not those that are too far away. In Utah, a block is typically 660 feet, so a radius of two blocks is covered in the quarter mile radius. Jurisdictions can adjust this radius based on local conditions. All businesses located within this buffer were assumed to have been affected by the transportation improvement project. Each affected business and its associated employment data were then put into a table that corresponded with the transportation project.

Running the model in ArcMap completed the business selection process for each project that was geo-referenced and created a table with all of the businesses that fell within a quarter-mile radius of each project. Using this table, the number of jobs for each of these business were then aggregated together for each year from 2000 to 2009. This information was then plotted along with the year the project was completed and the employment trend both before and after the project was completed. A screenshot of the GIS program, ArcMap 10.0, can be seen in Figure 2. The screenshot shows the selected project, the quarter mile radius buffer around it, and the selected businesses that lie within the buffer. Since the employment database only went through 


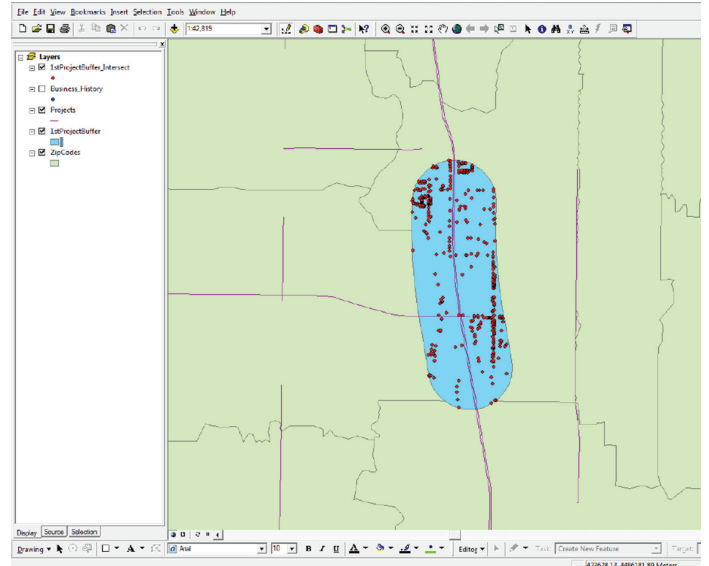

Figure 2: GIS Program with buffer and selected businesses.

the fourth quarter of 2009, it was determined that projects completed in 2009 would not be included in the analysis because there is not sufficient postconstruction data. This reduced the number of projects included in the employment analysis to 151 .

An example of the analysis completed for each project is shown in Figure 3. This plot shows the number of employees over the last 10 years along Redwood Road from 9000 South to 10400 South in West Jordan, Utah. The project was a reconstruction project that widened the corridor to four lanes and is the same project used as an example for the sales tax analysis.

In Figure 3, there are three trends presented. The trends describe employment in this area for (1) preconstruction (four years leading up to construction), (2) during construction, and (3) postconstruction of the project.

Figure 3 shows a negative trend in the number of local employees per state employees before the beginning of construction. This means that the local area was experiencing an employment growth that was 3.5 percent less per year than the state. After the project was completed, this was reduced to just 0.1 percent less than the state.

The same analysis was completed for each geo-referenced project. Using the completed analysis for each project, an overall average percent increase in employment after the completion of a transportation project was calculated.

4.4. Analysis Process. The analysis presented here provides a strong starting point to understand the economics of transportation in any jurisdiction, with the state of Utah used as a case study. The results, however, are limited by the availability of complete datasets for analysis. As such, in addition to reporting on the findings of the analysis performed, it is important to establish a formal process by which the economic impacts of transportation projects can be understood. The process developed in this study can be used to further improve the understanding and refine the relationships found in this study between transportation and economic impacts in any jurisdiction where sufficient data are available.

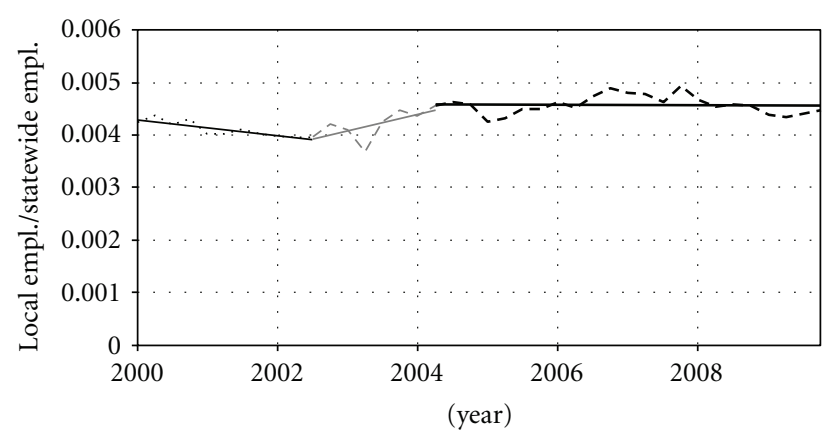

$$
\begin{aligned}
& \ldots \text { Local empl./statewide empl. preconstruction } \\
& --- \text { Local empl./statewide empl. postconstruction } \\
& - \text { Trend during construction } \\
& -- \text { Local empl./statewide empl. during construction } \\
& - \text { Preconstruction trend } \\
& - \text { Postconstruction trend }
\end{aligned}
$$

Figure 3: Number of employees near reconstruction project on Redwood Road.

The sales tax and employment analyses performed in this study followed similar steps. These steps have been defined, and a flow chart has been created that outlines these steps. Although the sales tax analysis did not use GIS to complete the analysis in this study, future analyses with more disaggregate data would be more easily completed in GIS. Figure 4 shows the flowchart outlining the steps followed in the analysis.

The six steps shown in Figure 4 and that should be followed in each analysis are outlined as:

(1) collect economic impact metric data and project information;

(2) geo-code the metric data and project information into a GIS database;

(3) use GIS model to gather all metric data located within a locally specified (14 mile in this analysis) radius of each project;

(4) normalize the metric data by state data to account for variability in the economy;

(5) calculate pre- and postconstruction trends of transportation project (using a timeframe determined by the local jurisdiction-four years in this analysis);

(6) compare for singular project analysis or use matched pairs $t$-test for multiple projects to determine if the trend after completion is significantly different from before.

It should be emphasized that good quality data are necessary for these analyses to provide an accurate evaluation of the economic impacts of the respective transportation project. Although some of the collected data were limited, the results are accurate considering the limitations. The focus of this study should be on the process used to generate the results. As additional data are gathered, the analysis can be completed again for more refined results. Sales tax data on a more disaggregate level and additional project location 
TABLE 1: Statistical findings summary.

\begin{tabular}{|c|c|c|c|c|c|}
\hline \multicolumn{6}{|c|}{ Statistical analysis } \\
\hline Analysis & Number of samples & Preconstruction trend & Postconstruction trend & Mean difference & $P$ value \\
\hline Sales tax & 331 & $-0.89 \%$ & $3.14 \%$ & $4.03 \%$ & 0.2039 \\
\hline Employment & 151 & $-3.45 \%$ & $1.08 \%$ & $4.53 \%$ & 0.2413 \\
\hline
\end{tabular}

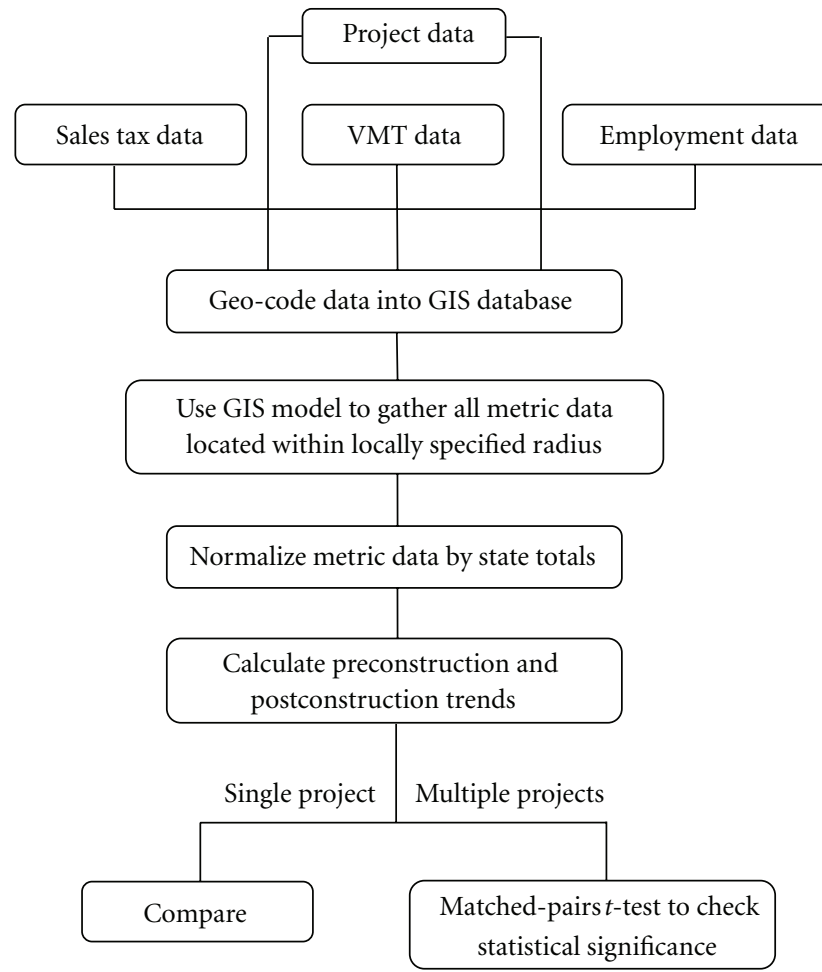

FIgURE 4: Flowchart of analysis process.

information would be the most beneficial in completing a future analysis.

\section{Statistical Analysis}

After completing the analysis, a matched-pairs $t$-test was used to determine if the results were statistically significant. A paired $t$-test was used because the preconstruction and postconstruction trends are compared for a certain location. The null and alternative hypotheses are as follows:

(i) $\mathrm{H}_{\mathrm{o}}$ : There is no difference between the means of the trends before and after;

(ii) $\mathrm{H}_{\mathrm{A}}$ : Trend After $>$ Trend Before.

Although none of the findings proved significant at a 95 percent confidence level, the results did show a positive relationship in employment and sales tax revenue after completion of a transportation project and are, therefore, considered practically significant. A summary of the results is shown in Table 1.

The mean difference between the two sales tax trends is 4.03 percent. The $P$ value is 0.2039 and the confidence interval for the mean is between -5.54 percent and 13.60 percent. The calculated $P$ value indicates that there is a 20.39 percent probability that the null hypothesis is true (which means there is a 79.61 percent probability that the alternative hypothesis is true and the postconstruction trend is greater than the preconstruction trend).

The employment analysis showed a mean difference of 4.53 percent. The $P$ value is .2413 and the confidence interval for the mean is between -8.19 percent and 17.26 percent. Since the confidence intervals for both the sales tax and employment analyses include 0 , it is possible that there actually is no difference between the preconstruction and postconstruction trends. The calculated $P$ value indicates that there is a 24.13 percent probability that the null hypothesis is true (which means there is a 75.87 percent probability that the alternative hypothesis is true and the postconstruction trend is greater than the preconstruction trend).

Although not statistically significant at a 95 percent confidence level, the results still suggest that the local economy experienced a boost in sales tax revenues compared to the trend of the state as a whole and are, therefore, considered practically significant by the authors.

\section{Project Type and Expenditure Value Breakdowns}

The results of the analysis can be further broken down into project types to determine if the type of project determined how large of an economic impact resulted from the transportation project. The overall project types are representative of the type of data available in the state of Utah. Other jurisdictions could adjust this to meet local needs. The six project types evaluated in this project and the number of samples for each category are as follows:

(1) signal and light (12 samples),

(2) maintenance (132 samples),

(3) safety (66 samples),

(4) bridge (38 samples),

(5) reconstruction/capacity (11 samples),

(6) other (72 samples).

The project type sales tax results are shown in Figure 5. The reconstruction/capacity projects experienced the greatest trend increase, while the signal and light and maintenance projects showed a slight decrease.

The employment analysis was also broken down into project type. The results of the analysis are shown in Figure 6 . The project type that experienced the greatest trend 


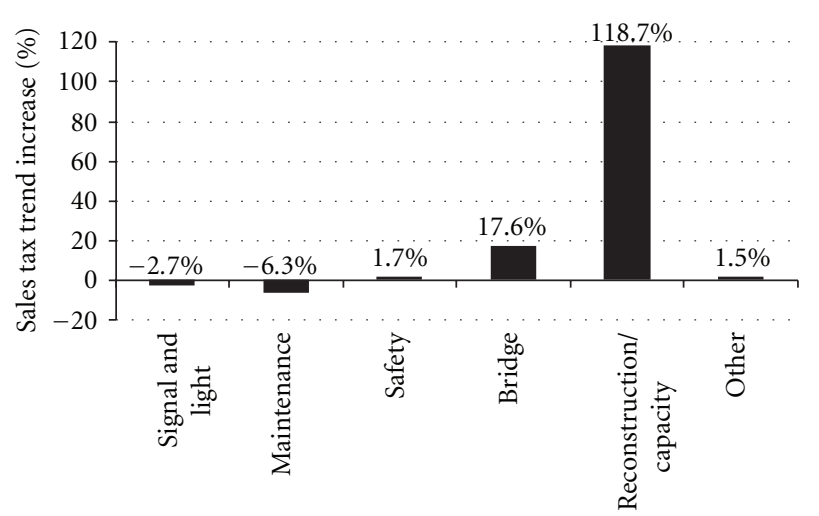

FIGURE 5: Project type sales tax trend increase results.

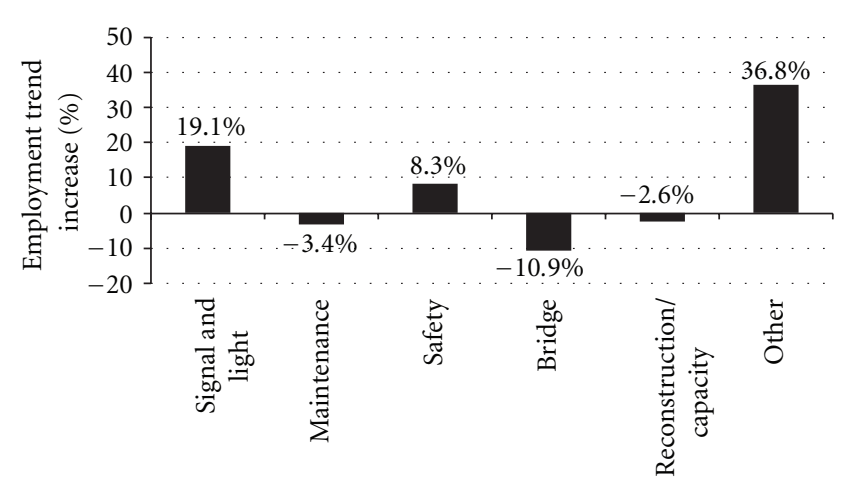

FIGURE 6: Project type employment trend increase results.

increase in employment is the category of other projects. Maintenance, bridge, and reconstruction/capacity projects showed a decrease in employment trends.

The sales tax and employment analyses were also broken down into expenditure categories. This was done to determine if more expensive projects yielded greater economic results. The expenditures were broken down into four groups. The four categories used in this project, along with the number of samples included in the sales tax analysis, are

(1) expenditures of less than $\$ 2,000,000$ (222 samples),

(2) expenditures between $\$ 2,000,000$ and $\$ 5,000,000$ (64 samples),

(3) expenditures between $\$ 5,000,000$ and $\$ 20,000,000$ (35 samples),

(4) expenditures greater than $\$ 20,000,000$ (10 samples).

Again, jurisdictions could identify project expenditure categories that fit the local data and needs of the jurisdiction.

The sales tax results broken down into these expenditure categories are shown in Figure 7. Projects that had expenditures between 2 and 5 million dollars experienced the greatest increase in sales tax trends. Projects with expenditures greater than 20 million dollars showed a slight decrease; however, there were only 10 projects analyzed that fell into this category.

The employment analysis was also broken down into expenditure categories. The results are shown in Figure 8 .

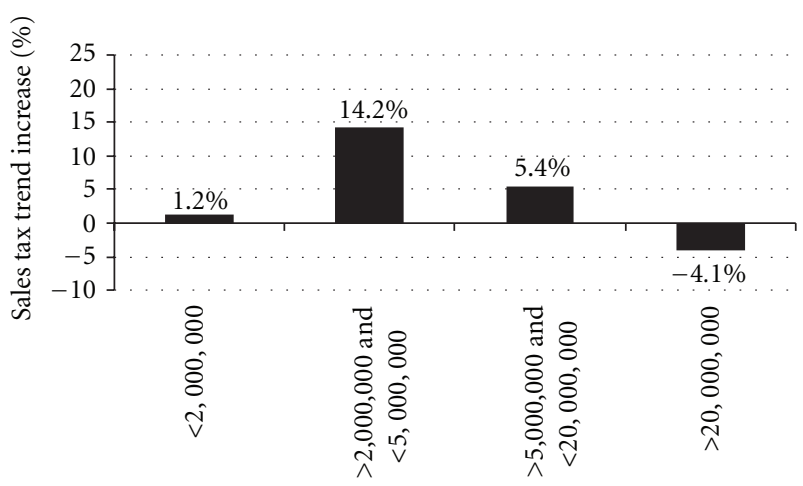

FIGURE 7: Expenditure category sales tax trend increase results.

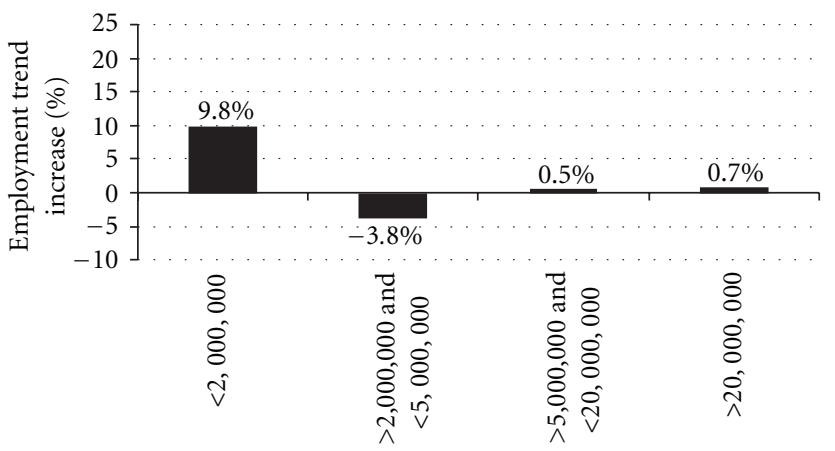

FIGURE 8: Expenditure category employment trend increase results.

Projects with expenditures of less than 2 million dollars showed the greatest increase in employment trends. Other categories showed a slight increase in employment trends except for projects with expenditures between 2 and 5 million dollars. That category showed a decrease of 3.8 percent.

The results of these analyses show that there is a positive relationship between transportation projects and sales tax revenues. Employment also showed a positive relationship with transportation projects.

Project type results showed a generally positive relationship with sales tax revenues, and reconstruction/capacity projects demonstrated the biggest impacts in sales tax revenues. Employment also showed a generally positive relationship with most project types, and other type projects showed the greatest increase in employment trends.

Expenditure category results demonstrated a generally positive relationship with sales tax revenues and employment. Interestingly, projects with expenditures between 2 and 5 million dollars showed the biggest increase in sales tax trends but also experienced the biggest decrease in employment trends.

\section{Conclusions and Recommendations}

This study effectively addresses a topic that has not been addressed in the literature. The results of this study indicate that there is a positive relationship between transportation improvement projects and sales tax revenues. Although 
the results were not determined to be statistically significant, the relationships of both sales tax and employment trends compared to the state were positive, indicating practical significance. As further analysis with more complete data is done, the exact nature of these relationships can be refined.

This study has prompted several recommendations intended to help UDOT (and other jurisdictions) better understand the economic impacts of transportation projects. Although this analysis provided a strong foundation and outlined a process to analyze economic impacts from transportation projects in Utah, additional studies need to be completed. Recommendations include:

(i) jurisdictions should evaluate the data input process for their project database to ensure that accurate project information and complete location data is being entered into the system;

(ii) jurisdictions should require that GPS coordinates be gathered for each project and recorded. This would provide exact and accurate location data and greatly simplify the geo-coding process;

(iii) state DOTs should develop and strengthen relationships with their local DWS and state tax commissions. This would allow access to sales tax data and employment data;

(iv) state DOTs should geo-code sales tax and employment data into a GIS database for further analysis;

(v) once quality data have been collected for three to four years (or time period specified by the local jurisdiction) previous to the beginning of a transportation project of interest, and three to four years after completion, complete the sales tax, employment, or other metric analyses as outlined in this paper.

\section{Future Research}

Economic data are increasingly becoming easier to obtain and in formats that are more conducive to analysis. As these data become available, additional research should be conducted to build upon the base provided in this paper and to further evaluate the economic impacts of transportation projects. Possible research areas for future research include (1) calculating a multiplier to indicate how much local sales tax or employment increases as the result of a specific investment in a transportation project, (2) disaggregating projects and developing a mathematical function that would capture the growth rate over time, and (3) dividing projects into internal (signal and light, safety, and other) and external (maintenance, bridge, reconstruction/capacity) projects to differentiate between local growth and state level growth.

\section{Acknowledgment}

The authors of this paper would like to acknowledge UDOT for providing the funding to complete this research. The contents of this paper reflect the views of the authors, who are responsible for the facts and accuracy of the information presented, and are not necessarily representative of the sponsoring agency.

\section{References}

[1] Cambridge Systematics Inc. (CSI), R. Cervero, and D. Aschauer, "Economic analysis of transit investments: guidebook for practitioners," Transit Cooperative Research Program. TCRP Report 35, Transportation Research Board of the National Academies, Washington, DC, USA, 1998.

[2] G. Weisbrod, "Evolution of methods for assessing economic development impacts of proposed transportation projects," in Proceedings of the $3 r$ International Conference on Transportation and Economic Development, 2006, http://www .edrgroup.com/images/stories/Transportation/weisbrod-evolution-of-mehtods-ted2006.pdf.

[3] G. G. Schultz, M. Saito, A. L. Stewart, and C. Siler, "Assessing the economic impacts of transportation improvement projects," Tech. Rep. UT-06.03, Utah Department of Transportation Research Division/Planning Division, Salt Lake City, Utah ,USA, 2006.

[4] G. G. Schultz and J. S. McGee, "Economic development criteria and project prioritization,” Tech. Rep. UT-09.07, Utah Department of Transportation Research Division, Salt Lake City, Utah ,USA, 2009.

[5] G. G. Schultz, J. S. McGee, and M. Saito, "Economic development criteria for use in the project prioritization process of Utah," in Proceedings of the Proceedings of the 7th Asia Pacific Conference on Transportation and the Environment (APTE '10), pp. 36-46, Semarang, Indonesia, 2010.

[6] Kansas Department of Transportation (KDOT), "Kansas department of transportation briefing paper: expanded highway project selection process," 2010, http://www.kansastlink.com/downloads/Project\%20Selection\%20Process\%20White\%20Paper.pdf.

[7] Cambridge Systematics Inc. (CSI), "Transportation improvements grow Wisconsin's economy: the economic benefits of transportation investments," Prepared for the Transportation Development Association of Wisconsin, 2003.

[8] P. Perlich, "Economic and demographic impacts of federally financed transportation infrastructure on the Wasatch Front," Economic and Business Review, vol. 64, no. 9-10, 2004.

[9] Cambridge Systematics Inc. (CSI), "Economic impacts of expanding public transportation in the Wasatch Front region," Prepared for Envision Utah, 2005.

[10] K. Gkritza, S. Labi, and K. Sinha, "Economic development effects of INDOT transportation projects," Final Report FHWA/IN/JTRP-2006/37, Purdue University, West Lafayette, Ind, USA, 2007.

[11] G. Weisbrod, "Distinguishing wide and local area business impacts of transportation investments," Transportation Research Record, no. 1552, pp. 27-31, 1996.

[12] Capital Professional Services, LLC., "Current consumer price index," http://www.inflationdata.com/inflation/consumer_price_index/currentcpi.asp. 


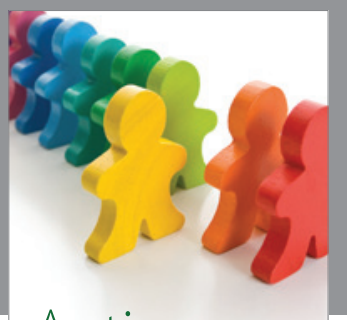

Autism

Research and Treatment
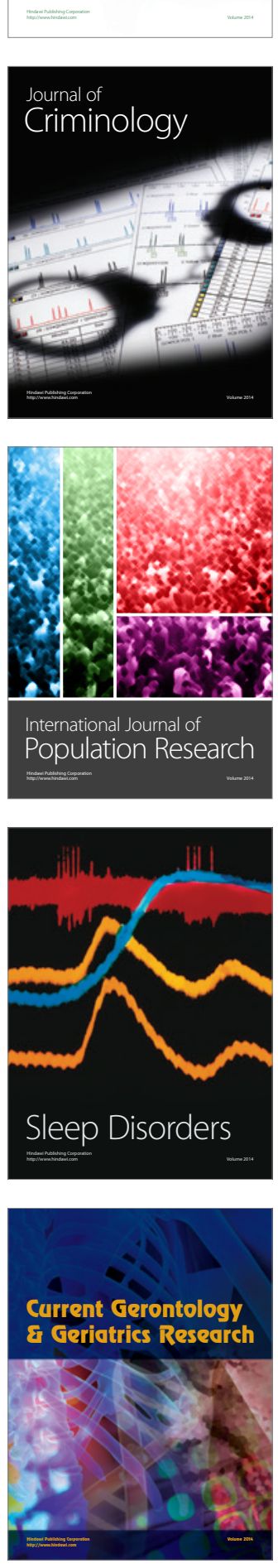
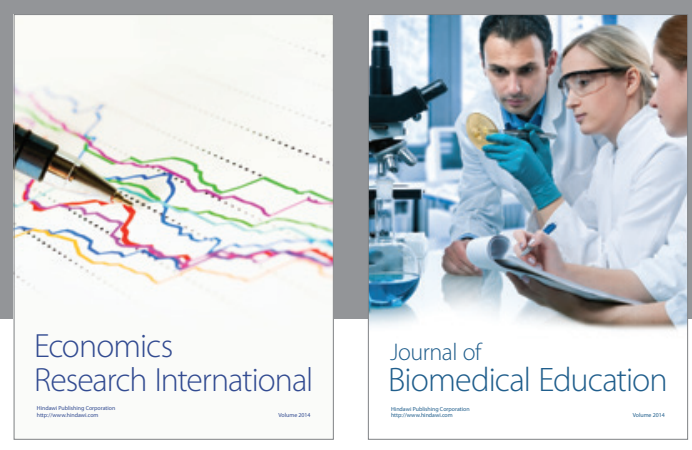

Journal of

Biomedical Education

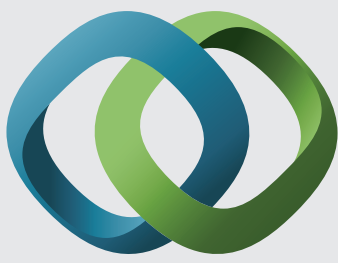

\section{Hindawi}

Submit your manuscripts at

http://www.hindawi.com
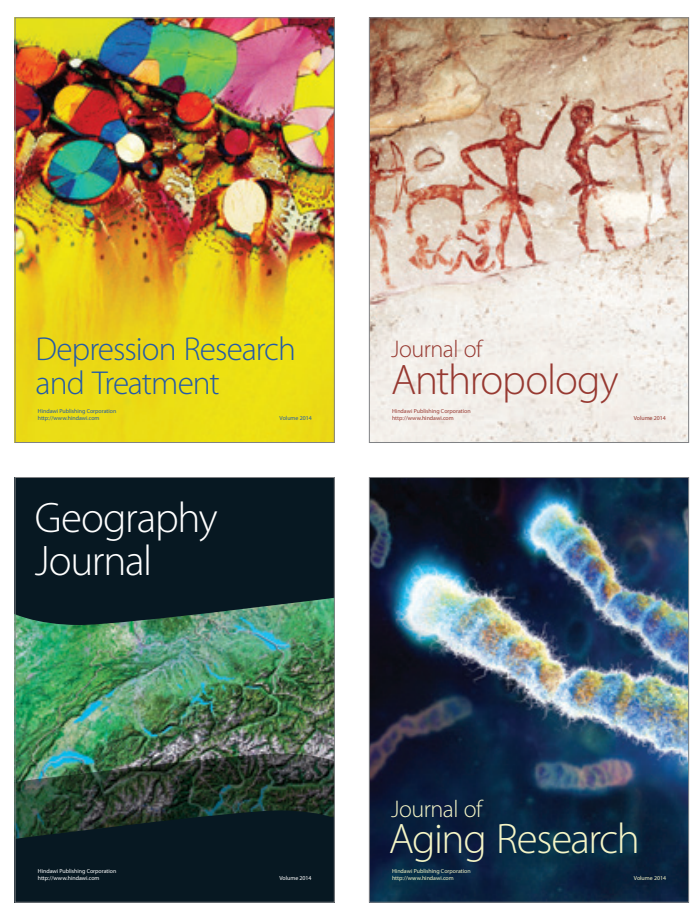

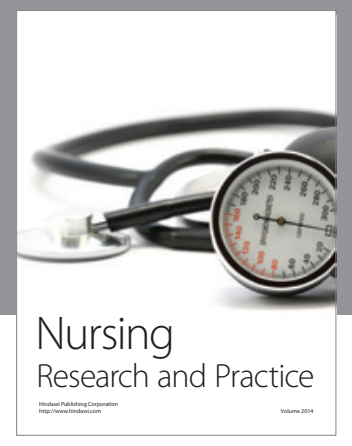

Nursing

Research and Practice

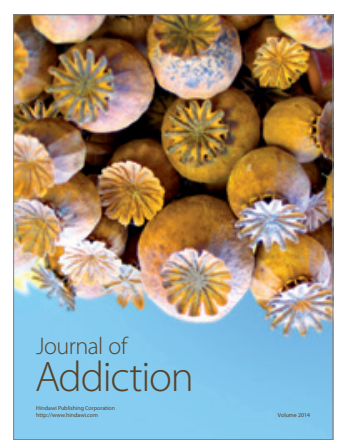

Child Development

Research

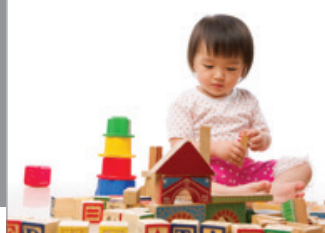

迥
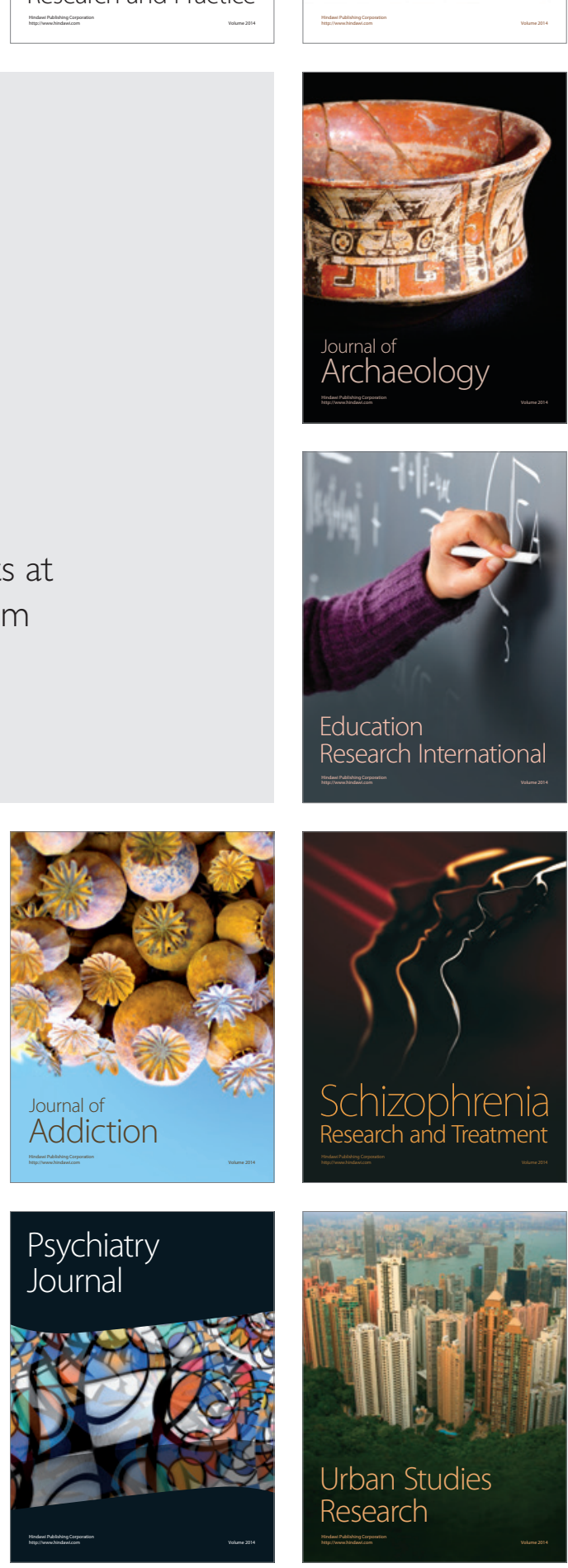